\title{
Addition Concept through the Lenses of Young Children: Creating Visual Representation with Digital Cameras
}

\author{
Kamariah Abu Bakar ${ }^{1 *}$, Faridah Yunus ${ }^{1}$, Suziyani Mohamed ${ }^{1}$, Aidah Abdul Karim ${ }^{1}$ \\ ${ }^{1}$ Faculty of Education, Universiti Kebangsaan Malaysia, Bangi, Selangor, MALAYSIA
}

Received 3 March 2020 - Accepted 8 April 2020

\begin{abstract}
Acquiring abstract Mathematics concepts is often challenging for young children. This study explored young children's use of digital cameras to exhibit their understanding of the addition concept. It investigated how the processes involved in producing the photographs and creating the visual representation that helped to develop the children's comprehension of the concept of addition. This study employed a qualitative research design and data collection included observation, dialogues with children and children's artefact (i.e. photographs). Six children in a preschool centre were participants for the focus group. The findings showed that young children were capable photographers and that their visual representation images supported their understanding of the addition concept. The study implicated that the creation of mathematical visual representation is critical to facilitate the development of abstract mathematics concepts.
\end{abstract}

Keywords: addition concept, young children, representation, technology

\section{INTRODUCTION}

Visualization has been highlighted as one of the most important skills in teaching and learning mathematics. This is because visualization help facilitates students in making sense of mathematical concepts. Additionally, visualization serves an imperative function in problemsolving, by facilitating students' comprehension of the mathematical problems that in turn assisting them to develop the mathematical concepts necessary to arrive at the solution (Abdullah, Zakaria, \& Halim, 2012; van Garderen, Scheuermann, \& Jackson, 2013). However, previous studies reported that students have limited visualization skills in mathematics (Arcavi, 2003; Stylianou \& Silver, 2004). Since visualization is a unique predictor of student's mathematics performance (Hawes, Moss, Caswell, Seo, \& Ansari, 2019; Kahl, Grob, Segerer, \& Möhring, 2019), it is suggested that visual representations should be emphasized in mathematics classrooms.

In line with the availability of various technology tools used in everyday life, a broad range of technology devices are increasingly introduced into educational settings worldwide to enhance students' visualization skills. The incorporation of visualization skills through the integration of technology tools and programs into teaching and learning practices has profited students of all grade levels (George \& Archontia, 2013; Khalid, Nawawi, \& Roslan 2009; Khalid, Karim, \& Husnin, 2018; Lokman, Nasri, \& Khalid, 2019; Ruhil Amal, Nor Fariza, \& Affendi, 2017) by enhancing students' engagement in learning (Milenković, Takači, \& Božić, 2020). Aligned with the constructivist theory of learning, technology incorporation into the classroom learning has been reported to empower children to construct their own knowledge, skills and understanding (Bakar \& Nasri, 2018; Khalid, Karim, \& Husnin, 2018). Hence, students can benefit from technology, particularly digital cameras, which offer aid to the quick generation of visual images when teachers and students utilize them in the classrooms. Therefore, the current research introduced a particular technological tool to explore the potential of a portable technology - the digital camera - used by preschool children to create visual representations. The purpose of embedding visualization with technology in learning is to provide visual representations that facilitate communication about important mathematics concepts to help students build a deep understanding of mathematics concepts. 


\section{Contribution to the literature}

- Introduces a portable technological tool to explore the potential of a portable technology - the digital camera - used by preschool children to generate visual representations.

- Offer insights into how constructivist principles and particular uses of representations are integrated in mathematics learning.

- Empowers educational leaders and classroom teachers to consider the integration of representations of all forms during mathematics instruction, including the use of digital cameras in teaching to support learning, particularly to facilitate understanding of mathematics concepts.

\section{RESEARCH BACKGROUND}

In young children's everyday life, they interact with a large range of visual images in many forms including watching television, browsing at magazines, reading storybooks, noticing picture advertisements and signboards in their surroundings. Clearly, visual images play important parts in young children's routines. Visualization is equally important in both the teaching and learning of mathematics (Zarzycki, 2004). "We could not even imagine introducing many mathematical concepts without illustrating them by pictures, drawings, graphs, etc." (Zarzycki, 2004, p. 108).

Representation is crucial in mathematics classrooms. Learning mathematics concepts is challenging for many students that resulted in the introduction of a range of representations such as manipulatives (physical and virtual), digital images and printed pictures, written and spoken symbols (Ahmad, Tarmizi, \& Nawawi, 2010; Bakar, Mohamed, Yunus, \& Karim, 2020; Elia, Gagatsis, \& Demetriou, 2007) to help children gain the concept. This is due to the powerful function of representation, both as an instructional tool as well as a learning tool to support the dissemination of mathematical ideas, conceptual understanding and problem solving (Elia et al., 2007). In many mathematics classrooms, teachers often use representation to enable active engagement of students in mathematical thinking; by probing students to explain and justify the representations they created. As for students, they use representations to access mathematical ideas and solve the given tasks.

The benefits of representation for learning and the existence of a large range of representations including physical and virtual manipulatives, both digital and printed images, verbal and written symbols, raises a great concern among teachers as students relied heavily on symbols to solve mathematical tasks (Mohamed \& Johnny, 2010). This is an alarming situation due to the fact that there is a strong connection between facility in utilizing multiple representations and conceptual understanding (Lesh, Post, \& Behr, 1987). Furthermore, we know only a little about young children's visual representations in mathematics context (Crespo \& Kyriakides, 2007; Woleck, 2001) predominantly pertaining to photographs creation and usage that shed light on young children's understanding for the topic of addition.

The purpose of incorporating visualization with technology (e.g. using digital cameras to create photographs) during learning is to afford students with visual representations to help facilitate communication of mathematics concepts that aid children build conceptual understanding. Since digital cameras are associated with many great features such as generating visual images quickly with little cost and conveniently retaking images and deleting them, it offers boundless opportunities in mathematics learning.

Previous studies have reported the positive link between incorporating digital cameras and using photographs and visual imageries with children's learning. For example, the use of photographs during literacy learning has facilitated children's literacy and language skills (Britsch, 2010; Byrnes \& Wasik, 2009). Photographic activities incorporated into classroom learning have sparked meaningful discussions among children (Marinak, Strickland, \& Keat, 2010). Students also tend to talk longer when explaining their pictures (Britsch, 2010). Hence, further studies incorporating digital cameras into learning should be conducted in other areas such as mathematics to ascertain the benefits.

Earlier researches have highlighted that the integration of a range of photographic activities into mathematics classrooms has led to rich mathematics learning (Bragg \& Nicol, 2011; Furner \& Marinas, 2012; Northcote, 2011; Orr \& Suh, 2013). Photographs used during problem-posing and problem-solving activities facilitate students' awareness pertaining to mathematics concepts found in daily routines as well as objects in their surroundings (Bragg \& Nicol, 2011; Orr \& Suh, 2013). Meanwhile, taking photos of outdoor scenes, events and objects offer valuable ways to help children apply the mathematics found in the environment into the classroom. These activities afford students with meaningful means to connect mathematical concepts with events and objects found in the surrounding (Northcote, 2011) without having to rely on teachers to demonstrate the association between the two (Furner \& Marinas, 2012). Also, such activities enable students to appreciate that mathematics is highly connected to their daily routines (Bragg \& Nicol, 2011), hence realizing the beauty of mathematics (Cuoco \& Curcio, 2001). In fact, 
photo-taking activities are relevant, fun and natural among children. When capturing photos, children make a critical decision about who and what images to be included, the stories embedded in the picture, hence building their own meaning of experiences (Piaget, 1955). This provides an essential opportunity to maximize children's learning engagement and experiences since exposures and experiences are vital in learning mathematical concepts.

Developing young children's arithmetic skills is critical in their early years of school (Patel \& Canobi, 2010; Resnick, 1992). Knowledge and skills obtained during their early years of instruction are beneficial in everyday life. Early counting experiences that children obtain through both informal and formal instructions are critical foundations towards understanding addition and more advanced mathematics concepts such as multiplication (Gelman \& Gallistel, 1978); as preparation for future learning and challenging life. The previous study found that there were learning implications in later years of school on those who had trouble understanding the addition concept in preschool; whereby pre-schoolers who struggled to perform addition operation continued to face difficulties solving addition tasks in Year One (Tyng, Zaman, \& Ahmad, 2011). Hence, it is imperative to ascertain whether visualization may have an important role in facilitating children's understanding of the addition concept compared to the ways it supports the understanding of geometry.

\section{THE STUDY}

The aim of this study is to examine the way visual mathematical representations support the young children's understanding of the concept of early numbers and engagement in addition activities within classroom contexts. The study was underpinned by the importance of visual representation for learning and the call for technology integration into young children's classrooms. Even though there are a number of researchers examining the children's usage of representation in mathematics learning, the researchers are restricted to a specific form of representation. Additionally, there are limited studies focusing on young children's usage of visual representation in mathematics context. Furthermore, the inclusion of digital cameras in this study is a part of the ways to equip young children with a dynamic learning culture as a preparation for the 21st- century life.

Specifically, the study explored how young children created and later used photographs to represent the addition concepts; as addressed in the research questions below:

1. What were the young children's dispositions toward using digital cameras?
2. What were the ways and to what extent did the young children's photographs portray their understanding of numbers and addition?

\section{METHODOLOGY}

This study involved six children (aged six years old) from a 'pre-school' in Malacca, Malaysia. These children were from the same classroom. Throughout this study, the researcher played a dual role as a; i) researcher as well as a; ii) teacher for this group of children. The remaining children who did not participate in this study continued the lesson with their classroom teacher. At the commencement of this study, the children had not been taught the topic of addition. They had just been learning and practicing counting. Following the three levels of representation - Enactive, Iconic and Symbolic (Bruner, 1960), the researcher began by introducing the addition concept using concrete materials. Children were given the opportunity to use a range of concrete objects to practice modeling various addition situations. Then, the children were required to create photographs of objects or events found in their surroundings to represent the addition concept. Next, children were introduced to the addition symbols (i.e. ' + ' and ' $=$ ' sign) and finally, they were prompted to write the addition equation (from little to no help from the researcher). By encouraging the children to exemplify their understanding of addition through various representation modes including concrete materials, photographs, and symbols, the children were actively self-discovering and constructing their mathematical understanding. The external representations (in the form of photographs created by the children) are the inferences of the children's internalization which enables the researcher to get insight into the children's understanding of addition; as external representations are linked to internal representations (Goldin \& Shteingold, 2001).

The children were introduced to digital cameras as easy and quick means to create visual images (in the form of photographs). The researcher began by introducing the basic parts of the digital cameras which are screen/viewfinder, memory card, lens and on/off button. The researcher also explained to the children the functions of each of the basic parts of the digital cameras. Next, the researcher demonstrated how to take photos to the children. The researcher reminded the children to always follow three safety and important rules prior to and when handling the cameras. The three rules are i) to always ensure putting the lanyard around the neck; ii) to stay still when photographing, and iii) to not touch the camera lenses. After practicing for quite some time, the children were able to produce photos that were considered as 'good' images.

Equipped with the digital cameras, the children were asked to capture addition situations that could be found in the school environment (without restricting them to 
any quantities and subjects to capture). Throughout the photographing sessions, the researcher continuously observed and recorded the children's dialogues, actions and behaviours. In fact, the researcher followed each child to their selected locations where they searched for objects or events that represented addition. The photographs produced by the children were important evidence that signified the children's understanding of the addition concept.

The data collected for this study comprised of children's photographs, observations, field notes, dialogues with children and video recordings. Firstly, all photographs taken by the children were analyzed. Based on the stilled photos, they were categorized into different ways children represented the set or group of objects. Then, the researcher proceeded with the video analysis of the different means of manipulating the objects demonstrated by the children to represent the addition situation. Observing what the children were doing and having dialogues with them were important data that explained the children's ways of thinking. The combination of all data was then summarised into a table; comprising photographs, behaviours, events and dialogues of each child that provided evidence for the child's ideas pertaining to the addition concept. The tables were beneficial to identify the link between each child's photographs and various data. Furthermore, the table enabled the researcher to compare and contrast photographs and ways of thinking among the children. The photographs and the processes involved in producing them afforded rich information pertaining to the children's understanding of addition.

\section{FINDINGS}

The introduction of digital cameras afforded the children with new experiences of exploring concepts and learning mathematics using technology tools. The digital cameras allowed the children to experience new, quick, easy and different ways of creating visual representation in mathematics classrooms. The photographing processes enabled the children's perspectives about addition to be explored.

\section{What were the Children's Dispositions towards Using Digital Cameras?}

The children were excited about having the opportunity to capture pictures by themselves. When informed that they will be given the digital cameras, one of them sought assurance from the teacher:

Aimy: "So, each of us will have the chance to capture pictures?"

After given the assurance that each child will have the turn to hold the cameras and take pictures, they expressed that they just could not believe that they now have the opportunity to 'play' with the device
Nadia: "Really?"

Qaisya: "Wow. I just couldn't believe it. We can take photos ourselves?"

The researcher again assured that each individual child will have the opportunity to take their favourite objects. The first practice task required the children to capture basic mathematics shapes in the classrooms to be familiar with the camera functions. The majority of the children began their 'hunt' immediately. Only a few children approached the researcher and required help with the digital cameras. When reviewing the photos, surprisingly the images of people recorded in the cameras outnumbered the images of shapes. The children were excited about having the cameras in their hands, hence they captured the images of friends, the researcher, the teacher and the assistant teacher. Also, many of the photos were blurry images because the children did not stay still when photographing pictures. After having explained the cause for the 'bad images', the photos recorded by the children showed improvements in quality.

It is important to note that the children treated the digital camera as a valuable tool. They used it appropriately. They always ensured that they themselves and their friends too obeyed the safety rules. When they found their peers were not following the rules highlighted by the researcher, they quickly reminded their friends to obey the rules. For instance, upon seeing Aimy was not staying still when capturing photos, Qaisya reminded her friend:

Qaisya: "Aimy...remember what the teacher said...you must not run, but stay still."

The children did not only capture photos, but they were also actively experimenting and exploring the other camera functions (that were not demonstrated by the researcher). The natural intuition had led them to discover the additional functions of the cameras.

A number of children perhaps had experienced taking pictures. For example, Nadia was observed exploring the camera functions and experimenting with the ways to enable her to view the pictures taken. After exploring the camera functions several times, she finally found how to view recorded images. Each time after taking pictures, she was observed viewing the images and capturing more pictures as she found the pictures were not satisfying. When she found the images taken were of good quality, she returned the cameras to the researcher signaling that she was satisfied with the quality of the photos and had completed the task.

On the other hand, Deliyana discovered the 'zoom' function as she was trying to capture the photos of objects that were located quite far from her. She was standing outside the classroom when she was attracted to the images of buckets across the field. However, she was standing far away from the buckets and if she had taken the images from her current position, the images 


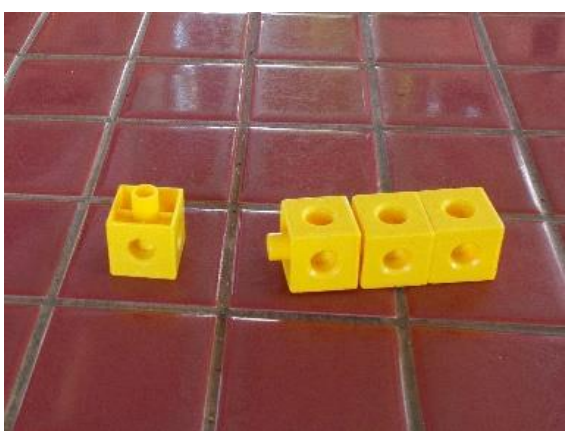

a) 3 (in a line) and 1 by Qaisya

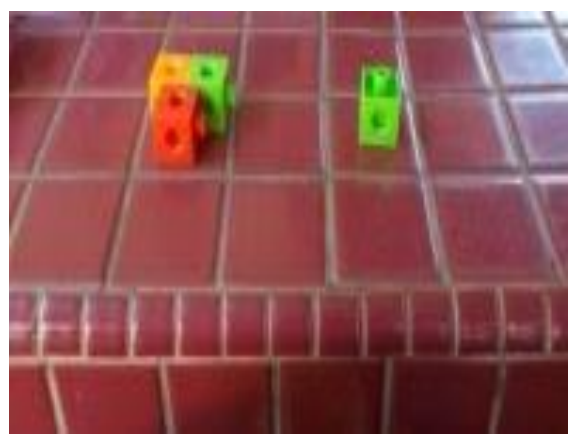

b) 3 (in a group) and 1 by Rozy

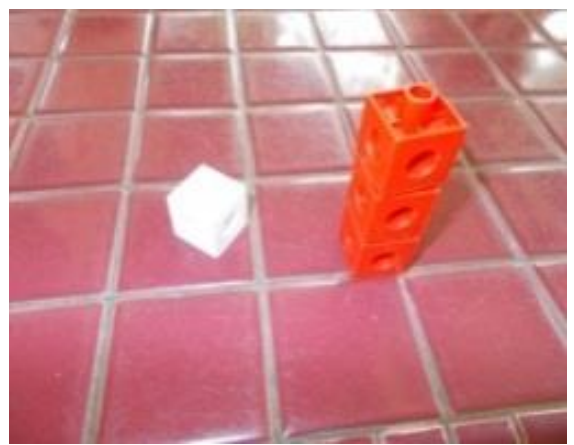

c) 3 (in a pile) and 1 by Aimy

Figure 1. Children's representations of addition using cubes, showing different ways of representing the first addend

of the buckets would have been very small. The difficulty led her to discover the 'zoom' function that resulted in capturing the picture clearly in the right size.

The natural intuition of the children to experiment and explore various functions of the cameras also created problems for the children. As a result of experimenting with various camera functions, Ali and Rozy had accidentally pressed the delete button and lost all the pictures they recorded.

\section{What were the Ways and to What Extent did the Young Children's Photographs Portray their Understanding of Numbers and Addition?}

It is important to note that the children were only recently being introduced to addition. Hence, the researcher started with an easy addition task aimed at initiating the children to explore addition by means of manipulating concrete objects. A basket of cubes was made available on the bench by the researcher and the children were required to represent a simple addition situation using the cubes.

The children were requested to represent the addends (3 and 1). In addition to representing both addends, the children were also required to find the sum. Without any difficulty, the children succeeded in demonstrating the addition situation. Note that the first addend (involving the quantity three) was represented in different forms i) horizontally (see Figure 1a), ii) grouped together (see Figure 1b), iii) vertically (see Figure 1c). Only the creations made by Qaisy, Rozy and Aimy were reported in this paper to represent all other children who produced similar forms of constructions. The children were able to see their friends' creations for the addition situation. However, none of them criticized the other's work, showing that they knew the quantities of the addends remained the same, despite having displayed in different forms.

As can be seen in Figure 1a, Qaisya connected the three cubes together and displayed them in a horizontal line. She then grabbed another cube and placed it apart from the first addend. As for Rozy, she grouped the three cubes together (see Figure 1b) and laid another cube far apart. Aimy slowly and carefully grabbed the cubes one by one while counting:

\section{“1,2,3."}

She then linked the cubes and formed a vertical structure (refer Figure 1c). She continued exhibiting the second addend by placing one cube next to her vertical cubes but leaving a gap between the two addends. Noticing that all children seemed satisfied and confident that they had modeled the addends correctly, the researcher asked the children to find the sum for the addends they constructed. All children were observed to count aloud. They counted the cubes for the first addend, one-by-one (" $1,2,3$ ") and proceeded to count the second addend (" 4 ") and arrived at the total ("4). The children's constructions showed that they identified addition as comprising of two sets or groups of objects. As for finding the total, they performed 'counting all' as the addition strategy.

Afterward, the children were asked to search for other objects to represent addition situations. Interestingly, the children selected a variety of subjects in their surroundings including cubes, coins, picture cards and kernels. A number of children chose the objects provided by the researcher as the subjects. As can be seen in Figure 2a, Norman chose to use coins made available by the researcher to represent the addition situation. Rozy selected cubes to complete the task (refer to Figure 2b). As for other children like Nadia, she seemed to plan to have other objects to be included in her addition photograph (than those provided by the researcher), thus went for a walk near the classroom. Nadia was attracted to the kernels she found on the ground (see Figure 2c) and told the researcher that she 


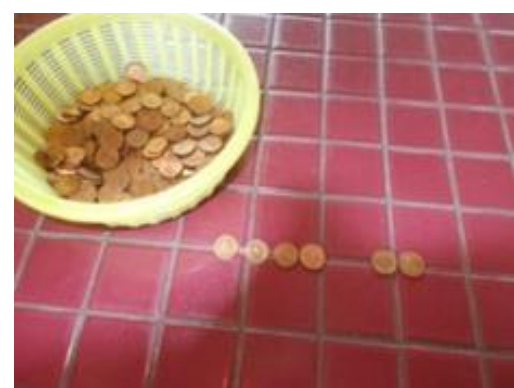

a) Photographing coins (4 and 2 made 6 ) - by Norman

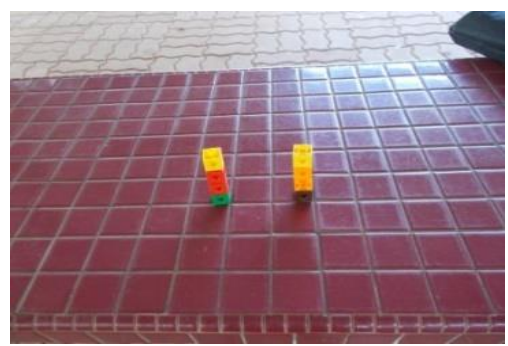

b) Photographing cubes (4 and 4 made 8 ) -by Rozy

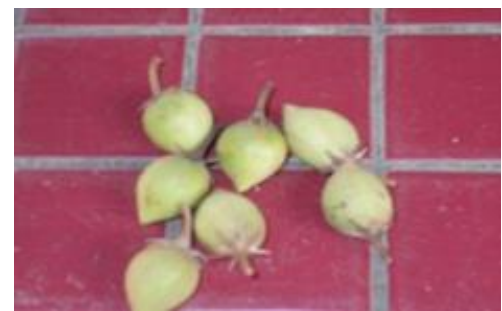

c) Photographing kernels (4 and 3 made 7)- by Nadia

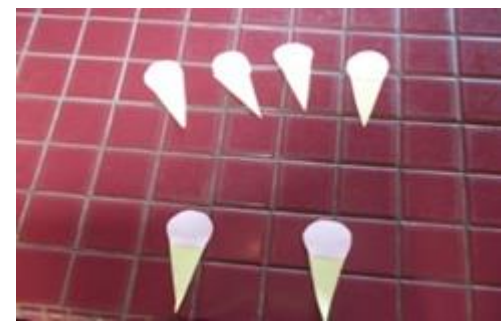

d) Photographing (4 and 2 made 6 ) - by Aimy

Figure 2. Photographs captured by the children to represent addition situation

finally knew what to capture. Aimy selected picture cards (ice cream picture cards) made by the researcher (see Figure 2d).

In their attempt to photograph the addition situation, the children were observed to first manipulate the subjects, then to capture the photos of their creations. The children carefully formed the quantities needed for the addends and the totals. There were children who moved the objects and transferred them to the other locations. The action was required when a child wanted to excerpt a specific quantity of objects from its group to enable him or her to achieve a specific quantity. There were times in which the children needed to combine a number of objects to form a quantity. For example, Norman grabbed four coins from the basket and put them in a line. Next, he picked two more coins and displayed them on the bench. Note that there is a clear gap between the first addend and the second addend (see Figure 2a). As for Rozy, she carefully took out some cubes and simultaneously counted:

" $1,2,3,4$ ", while linking the cubes together to create a structure (refer to Figure $2 b$ ).

She made another structure using the same quantities of cubes and repeated the same count starting from 1 until she reached 4 . When asked to define the building she created and explain what she was doing, proudly she said that:

"they are hotels. "1,2,3,4, ..5,6,7,8", ... " 8 ".

The external visual representation (i.e. the cubes) she created was her attempt to represent the real-world structure (she identified as hotels). Clearly, she 'counted all' when she wanted to tell the researcher the total (see Figure 2b). Similarly, Nadia and Aimy manipulated their chosen objects as former children. However, Nadia provided no obvious counting gestures. On the other hand, Aimy performed the counting aloud during their count for the first addend, and continued 'counting oneby-one' for the second addend. When needed to prove to the researcher that she managed to find the total accurately, Aimy performed counting-all. After being satisfied that they had created the correct addition situation and were confident that the totals were correct, the children photographed their creations. It is important to note that all children included appropriate contexts for addition and the correct answers. They also used a variety of contexts involving real-life examples for their stories. In this study, the creation of mathematical images in the form of photographs required the children to create an addition situation concretely. Evidently, the children used their visualization skills during the construction of relevant images (using manipulatives) and using them appropriately for mathematical understanding (manipulating them to help develop an understanding of addition).

\section{DISCUSSION OF FINDINGS}

The findings of this study showed that the usage of visual representations (with the aid of technology tooldigital camera) by the young children provided insights into their understanding of numbers and addition concepts. The children's manipulation of a range of objects during the photography tasks had aided children in developing their understanding of the concept of numbers and addition.

\section{Young Children as Photographers}

As evidenced in this study, the young children were capable of taking photographs using digital cameras after being demonstrated how to operate the tool only during one introduction session. Interestingly, children are independent users of technology (Blagojevic \& Thomes,2008). This is because digital cameras are easy 
tools that can be operated by young children (Orr \& Suh, 2013). In fact, these children were capable of exploring other functions and used them successfully despite only being shown the basic camera functions. As apparent in the study by Barker and Smith (2012), children are good photographers.

As observed in this study, children were responsible users of technology. They even reminded other friends to handle the camera with good care. As asserted by Blagojevic and Thomes (2008), children did not treat the camera as a toy but with respect. Such behaviors clearly show the benefit of providing children access to an "adult" tool (Stephenson, 2009).

The findings of this study support the claim that photography is a great tool to be used in young children's classroom (Byrnes, 2009). Integrating photos into learning is beneficial, because photographs permit young children to communicate their thinking and perspectives, experiences and understanding (Pyle, 2013; Serriere, 2010). Particularly, photography activities that are incorporated into mathematics learning facilitate learners to "see the beauty and excitement in mathematics" (Cuoco \& Curcio, 2001, p. xiii) as their active engagement in the photography process which enables children to experience meaningful learning that links mathematics with everyday activities. Additionally, one of the advantages of using digital cameras as highlighted by Murray (2008) is the 'immediacy'. The benefits of having the opportunity to review instantly the images she captured enabled Nadia to self-asses the task given to her. When the photo reviews showed quality pictures, she knew that she had completed the task successfully.

\section{Children's Understanding of Numbers and Early Understanding of Addition}

In order to examine children's conceptual understanding, this study intended to sort evidence for the children's concept formation for the concept of addition. The children's actions as well as behaviours observed when performing counting enabled the researcher to identify whether the children had accomplished the addition tasks resulting from the steps they memorized or really attempted solving the tasks with understanding.

The children's manipulations of various objects for the addition task during the photographing activities proved their understanding of quantity. When constructing the addends with various objects, the children's counting acts and behaviours demonstrated the one-to-one principle. This is because they touched or pointed to each object while saying their individual number name. By counting 'one by one' and finally verbalized the last number as the total quantity, their counting behaviours provided evidence for the cardinality principle (Batchelor, Keeble, \& Gilmore,
2015). After constructing the quantities in various forms including in a line as well as a group, the children clearly demonstrated that the last number verbalized for the sets or groups designated the sum for objects (i.e. expressions of cardinality principle).

Additionally, it was indicated that the children possessed a stable understanding of quantity. Particularly when attempting to solve various tasks (involving quantities below 10), the children successfully completed the posed tasks. Also, the formation of quantities in the form of a vertical or horizontal line and in groups exhibited further evidence for the steady understanding of quantities of small numbers.

The findings of the present study showing that the children had formed a conceptual understanding of addition, is aligned with the previous study reported by Hughes (1981) whereby demonstrated the young children's capability to solve simple addition tasks prior to formal instruction. Likewise, the study conducted by Ibarra and Lindvall (1982) involving kindergarten children reported these young children's ability to perform simple addition prior to entering formal education. This shows that the children in the study possessed some procedural knowledge pertaining to the concept of addition. In addition, they perhaps had conceptual knowledge of addition, particularly concerning small quantities, due to the children's routines and daily experiences including shopping in supermarkets and observing adults' activities. As asserted by Anghileri (2000), everyday situations that involve manipulating objects (while counting) have helped children to develop knowledge of addition.

\section{The Strategy of 'Counting-all' for Addition}

Counting is important in performing addition (Baroody, 1987a). Taking into account that counting and adding are interconnected whenever doing addition, this study distinguished these mathematical actions to enable the identification of the children's conceptual understanding of addition.

As Butterworth (2005) affirmed, counting is the key to various arithmetic skills. Counting experiences that require children to join or combine groups of objects and counting the sets altogether to obtain the total, support the students' understanding of addition as an incrementing process (Baroody \& Wilkins, 1999). Moreover, 'counting is a developmental foundation for fluent addition' (Eisenhardt et al., 2014. p. 501), hence meaningful counting experiences will progressively help students develop skills and concepts of addition. Not surprisingly, the children in the current study were capable of employing 'count-all' to arrive at the total because as stated by Hughes (1981), children have addition knowledge prior to entering school. The young children in this study readily possessed an intuitive understanding of addition, in which they obtained 
through everyday exposures, observation and experiences.

Although the children's construction involved a range of real objects, their creations alone could not be used entirely as evident for their understanding of addition. Therefore, further analysis of the children's verbal counting whilst creating the addition situation was done. Furthermore, it is vital to identify that the children counted the objects to add rather than simply counting (i.e. saying aloud the number names) because both the act of counting and adding intricate finding the cardinality of a set of objects. In this study, clearly the children employed 'counting-all', whereby they began with counting the first set of objects, later counting the second set, and finally arrived at the total (e.g. Rozy and Aimy). By performing the addition strategy, the children demonstrated proofs for addition skills and knowledge. Obviously, the children did not simply perform the count (as a series of numbers that they memorized), but they purely counted to add. Siegler and Jenkins (1989) listed eight strategies of addition used by young children, where the majority of them (i.e. five strategies) require the act of counting. Bearing in mind that the children in the present study had limited exposures to addition and it was only recently that they experienced and explored addition, it was possible they started with 'counting-all' and frequently employed this strategy when attempted all addition tasks. Also, as reported by Baroody (1987b), 'counting-all' is among the strategies that are easy to use by young children. Indeed, this strategy is also one of the most popular strategies used for addition not only among young children, but also older children in higher grades.

The photography task required the children to manipulate a range of concrete materials that can be found in the school environment; hence necessitate mathematical visualization. Zazkis, Dubinsky, and Dautermann (1996) asserted visualization as an act that "consists of the construction, on some external medium such as paper or objects or events that the individual identifies with objects or processes in her or his mind" (p. 441). The children's creation of the addition situation using concrete materials (e.g. cubes) and the manipulation of the objects signaled that the children had some knowledge of addition situations. In addition to the external visual representations created by the children, the counting behaviours that they demonstrated and verbalized provided further evidence for addition understanding. As asserted by Zahner and Corter (2010) external inscriptions may be used for various purposes, including representing numerical and making abstract relationships concrete. The findings showed that the creation of visual representations contributed to understanding the addition concept especially when the concept is abstract. In this study, providing children with digital cameras to create visual representations of addition situations (found in the children's surroundings) facilitated them in understanding addition. This is because the children were involved in the process of mathematical visualization that required the children to form images (with a variety of concrete materials) and using such images effectively for learning and understanding. Obviously, visualization help renders abstract mathematical concepts concrete and through this concrete representation, students understand abstract concepts" (Macnab, Phillips, \& Norris, 2012).

\section{CONCLUSION, IMPLICATIONS AND RECOMMENDATIONS}

This study explored the children's representations that shed light on the important aspects of the children's skills and knowledge that provided evidence for their understanding of numbers and the addition concept. By incorporating digital cameras, this study investigated the ways photographs supported the young children in attaining an understanding of early numbers and the addition concept during their engagement in photography activities. The findings from this study clearly reveal the students' ability to make sense of the concept of addition that was enriched through the construction of visual representation (assisted by digital cameras). Furthermore, this study acknowledged the potential of photographs in providing insight into both children's understanding of quantities as well as basic addition skills and strategy. The study also emphasized the importance of valuing and supporting the early development of children's creation of visual mathematical representations to facilitate their understanding of mathematics concepts.

The findings of this study exhibited that the children's number knowledge and skills were critical for understanding the concept of addition. Hence, tasks that required the children to explore mathematics in the real world (e.g. in the school environment) had indeed broadened their mathematical thinking and experiences. The children's understanding of the mathematics concept expanded. Initially, the children focused only on the objects they had worked with, and later they proceeded to work with many real objects in the environment. Manipulating various objects had indeed facilitated the children's early understanding of addition (e.g. addition as i) comprising two sets of objects and ii) combining the groups of objects. After manipulating a range of objects, the children gradually progressed to possessing more knowledge of addition (e.g. 'countingall' to add). Despite the fact that the children had limited addition strategies, this provided important information that exhibited a basis on which to build, since the children were newly introduced to the concept of addition.

This study has implications for the constructivist theory of learning. The children's active engagement 
with various objects in their surroundings as well as selfexploration of the learning environment enabled the children to experience meaningful learning by making sense of the addition concept themselves. In particular, the manipulation of a large range of real objects supported the development of the children's conceptual understanding of addition. In addition, mathematics books used in young children's classrooms should be enriched with a variety of visual representations including pictures and diagrams. This is because these pictures and diagrams could help reduce the level of cognitive load especially when learning abstract mathematics concepts.

The findings from this study demonstrating the students' mathematical sense with the help of visual representation have implications for teachers' practices involving instructions and assessments employed in mathematics classrooms. Children in the same classroom vary in many aspects including knowledge, skills, learning styles and preferences. Rather than relying heavily on one particular teaching approach, teachers should consider appreciating various teaching approaches and strategies so the children could obtain maximum benefits when instructions attended to the differences that children had. In the Malaysian context, mathematics teachers still practice traditional teaching approaches and strategies that put emphasis on symbol use with little freedom for students to choose their preferred representation modes, appreciate correct answers in problem-solving rather than value the means and processes to arrive at the solution, and restrict children to the representation modes and strategies taught by the teachers with little support in helping students experience the most meaningful means for making sense of mathematics concepts. Additionally, in line with The National Standard Preschool Curriculum that highlights the importance of supporting children to learn mathematics concepts with understanding, teachers should include real-life examples into mathematics teaching and learning as such practices are beneficial in supporting children to make sense of mathematical concepts and connecting mathematics with everyday lives. The potential of many technology tools to support learning should be incorporated into the children's learning to facilitate meaning-making processes as well as concept-developing.

Future research should include a comparison of representation usage in other mathematics areas of early mathematics. This is because the efficiency of a particular or a number of representation modes may vary for different topics and hence it is beneficial that teachers have the information to plan effective learning experiences for the children.

Most importantly, both teachers and students should appreciate all modes of mathematical representation equally. Even though there is a particular form of representation that could be the most effective for attempting a particular task at hand, other representation forms that are helpful in arriving at the solution should also be considered.

\section{ACKNOWLEDGEMENT}

This research was supported by grants provided by the Faculty of Education, Universiti Kebangsaan Malaysia (GG-2019-011) and (GG-2019-061).

\section{REFERENCES}

Abdullah, N., Zakaria, E., \& Halim, L. (2012). The effect of a thinking strategy approach through visual representation on achievement and conceptual understanding in solving mathematical word problems. Asian Social Science, 8(16), 30-37. https:// doi.org/10.5539/ass.v8n16p30

Ahmad, A., Tarmizi, R. A., \& Nawawi, M. (2010). Visual representations in mathematical word problem solving among form four students in Malacca. Procedia-Social and Behavioral Sciences, 8, 356-361. https:// doi.org/10.1016/j.sbspro.2010.12.050

Anghileri, J. (2000). Teaching number sense. Trowbridge, Wiltshire: Cromwell Press.

Arcavi, M. (2003). The role of visual representations in the learning of mathematics. Educational Studies in Mathematics, 52(3), 215-241. https://doi.org/ 10.1023/ A:1024312321077

Bakar, K. A., Mohamed, S., Yunus, F., \& Karim, A. A. (2020). Use of Multiple Representations in Understanding Addition: The Case of Pre-school Children. International Journal of Learning, Teaching and Educational Research, 19(2). https://doi.org/ 10.26803/ijlter.19.2.18

Bakar, N. A. \& Nasri, N. M. (2018). Pendidikan sains awal kanak-kanak berbantukan teknologi maklumat dan komunikasi (TMK) dalam proses pengajaran dan pembelajaran di kelas prasekolah (Assisted information technology and communication (ICT) early science eduaction for preschool classes). Paper presented at the International Conference on Social Studies $\mathcal{E}$ Humanities (ICOSH 2018).

Barker, J., \& Smith, F. (2012). What's in focus? A critical discussion of photography, children and young people. International Journal of Social Research Methodology, 15(2), 91-103. https:/ / doi.org/10.1080 /13645579.2012.649406

Baroody, A. J. (1987a). Children's mathematical thinking: A developmental framework for preschool, primary, and special education teachers. New York: Teachers College Press.

Baroody, A. J. (1987b). The development of counting strategies for single-digit addition. Journal for 
Research in Mathematics Education, 18(2), 141-157. https:/ / doi.org/10.2307/749248

Baroody, A. J., \& Wilkins, J. L. (1999). The development of informal counting, number, and arithmetic skills and concepts. In J.V. Copley (Ed.), Mathematics in the early years (pp. 48-65). Reston, VA: National Council of Teachers of Mathematics.

Batchelor, S., Keeble, S., \& Gilmore, C. (2015). Magnitude representations and counting skills in preschool children. Mathematical Thinking and Learning, 17(23), 116-135. https://doi.org/10.1080/10986065. 2015.1016811

Blagojevic, B., \& Thomes, K. (2008). Young photographers. YC Young Children, 63(5), 66.

Bragg, L. A., \& Nicol, C. (2011). Seeing mathematics through a new lens: Using photos in the mathematics classroom. Australian Mathematics Teacher, 67(3), 3-9.

Britsch, S. (2010). Photo-booklets for English language learning: Incorporating visual communication into early childhood teacher preparation. Early Childhood Education Journal, 38(3), 171-177. https:/ / doi.org/10.1007/s10643-010-0412-2

Bruner, J. S. (1960). The process of education. Cambridge: Harvard University Press.

Butterworth, B. (2005). The development of arithmetical abilities. Journal of Child Psychology and Psychiatry, 46(1), 3-18. https://doi.org/10.1111/j.1469-7610. 2004.00374.x

Byrnes, J., \& Wasik, B. A. (2009). Picture this: Using photography as a learning tool in early childhood classrooms. Childhood Education, 85(4), 243-248. https:// doi.org/10.1080/00094056.2009.10523090

Crespo, S. M., \& Kyriakides, A. O. (2007). To draw or not to draw: Exploring children's drawings for solving mathematics problems. Teaching Children Mathematics, 14(2), 118-125.

Cuoco, A., \& Curcio, F. R. (2001). The roles of representation in school mathematics. Reston, VA: National Council of Teachers of Mathematics.

Eisenhardt, S., Fisher, M. H., Thomas, J., Schack, E. O., Tassell, J., \& Yoder, M. (2014). Is it counting, or is it adding? Teaching Children Mathematics, 20(8), 498507. https://doi.org/10.5951/teacchilmath.20.8. 0498

Elia, I., Gagatsis, A., \& Demetriou, A. (2007). The effects of different modes of representation on the solution of one-step additive problems. Learning and Instruction, 17(6), 658-672. https://doi.org/ 10.1016/j.learninstruc.2007.09.011

Furner, J. M., \& Marinas, C. A. (2012). Learning math concepts in your environment using photography and GeoGebra. Paper presented at the International Conference on Technology in Collegiate Mathematics.
Retrieved from http://archives.math.utk.edu/ ICTCM/VOL25/S125/paper.pdf

Gelman, R., \& Gallistel, C. (1978). The children's understanding of number. Cambridge, MA: Harvard University Press.

George, A., \& Archontia, M. (2013). Educational technology as a teaching and learning tool in environmental education. International Journal of Academic Research in Business and Social Sciences, 3(9), 191. https:// doi.org/10.6007/IJARBSS/v3-i9 /201

Goldin, G., \& Shteingold, N. (2001). Systems of representations and the development of mathematical concepts. In A.A. Cuoco \& F.R. Curcio (Eds.), The roles of representation in school mathematics (pp 1-23). Reston, VA: NCTM

Hawes, Z., Moss, J., Caswell, B., Seo, J., \& Ansari, D. (2019). Relations between numerical, spatial, and executive function skills and mathematics achievement: A latent-variable approach. Cognitive Psychology, 109, 68-90. https://doi.org/10.1016/ j.cogpsych.2018.12.002

Hughes, M. (1981). Can preschool children add and subtract? Educational Psychology, 1(3), 207-219. https:/ / doi.org/10.1080/0144341810010301

Ibarra, C. G., \& Lindvall, C. M. (1982). Factors associated with the ability of kindergarten children to solve simple arithmetic story problems. The Journal of Educational Research, 75(3), 149-156. https:/ / doi.org /10.1080/00220671.1982.10885372

Kahl, T., Grob, A., Segerer, R., \& Möhring, W. (2019). Executive functions and visual-spatial skills predict mathematical achievement: Asymmetrical associations across age. Psychological Research, 1-11. https:// doi.org/10.1007/s00426-019-01249-4

Khalid, F., Nawawi M. H. \& Roslan, S. (2009). Integration of ICT in Malaysian secondary schools: What conditions will facilitate its use? International Journal of Learning, 15(2), 85-94. https://doi.org/ 10.18848/1447-9494/CGP/v15i12/46043

Khalid,F., Karim, A.A., \& Husnin,H. (2018). Pre-Service teachers' preparedness in integrating pedagogy, content and technology knowledge. Journal of Advanced Research in Dynamical \& Control Systems, 10(2), 1467-1473.

Lesh, R., Post, T., \& Behr, M. (1987). Representations and translations among representations in mathematics learning and problem solving. In C.Janvier (Ed.), Problems of representation in the teaching and learning of mathematics (pp. 33-40). Hillsdale, NJ: Erlbaum.

Lokman, H.F., Nasri, N.M., \& Khalid, F. (2019). The effectiveness of using twitter application in teaching pedagogy: A meta-synthesis study. International Journal of Academic Research in Progressive Education and Development, 8(2), 205-212. 
Macnab, J. S., Phillips, L. M., \& Norris, S. P. (2012). Visualizations and visualization in mathematics education. In S. P. Norris (Ed.), Reading for evidence and interpreting visualizations in mathematics and science education (pp. 103-122). Rotterdam: Sense Publishers. https:/ / doi.org/10.1007/978-94-6091-9 24-4_6

Marinak, B. A., Strickland, M. J., \& Keat, J. B. (2010). A Mosaic of words: Using photo-narration to support all learners. Young Children, 65(5), 32-36.

Milenković,A., Takači, D. \& Božić, R. (2020): On the influence of software application for visualization in teaching double integrals, Interactive Learning Environments. https:/ / doi.org/10.1080/10494820. 2020.1719164

Mohamed, M., \& Johnny, J. (2010). Investigating number sense among students. Procedia-Social and Behavioral Sciences, 8, 317-324. https://doi.org/10.1016/ j.sbspro.2010.12.044

Murray, S. (2008). Digital images, photo-sharing, and our shifting notions of everyday aesthetics. Journal of Visual Culture, 7(2), 147-163. https://doi.org/ $10.1177 / 1470412908091935$

Northcote, M. (2011). Step back and hand over the cameras! Australian Primary Mathematics Classroom, $16(3), 29$.

Orr, J., \& Suh, J. (2013). A picture is worth 100 Math ideas. Teaching Children Mathematics, 19(7), 458-460. https://doi.org/10.5951/teacchilmath.19.7.0458

Patel, P., \& Canobi, K. H. (2010). The role of number words in preschoolers' addition concepts and problem-solving procedures. Educational Psychology, 30(2), 107-124. https://doi.org/ 10.1080/01443410903473597

Piaget, J. (1955). The construction of reality in the child. Journal of Consulting Psychology, 19(1), 77. https: / / doi.org/10.1037/h0038817

Pyle, A. (2013). Engaging young children in research through photo elicitation. Early Child Development and Care, 183(11), 1544-1558. https://doi.org/ $10.1080 / 03004430.2012 .733944$

Resnick, L. B. (1992). From protoquantities to operators: Building mathematical competence on a foundation of everyday knowledge. In $G$. Leinhardt, R. Putnam \& R. A. Hattrup (Eds.), Analysis of arithmetic for mathematics teaching (pp. 373-429). Hillsdale, NJ: Lawrence Erlbaum Associates, Publishers.

Ruhil Amal, A., Nor Fariza, M. N., \& Afendi, H. (2017). Metacognitive online reading and navigational strategies by science and technology university students. GEMA Online Journal of Language Studies,
17(3), 18-36. https:/ / doi.org/10.17576/gema-2017$1703-02$

Serriere, S. C. (2010). Carpet-time democracy: Digital photography and social consciousness in the early childhood classroom. The Social Studies, 101(2), 60 68. https:/ / doi.org/10.1080/00377990903285481

Siegler, R. S., \& Jenkins, E. (1989). How children discover new strategies. Hillsdale, NJ: Erlbaum.

Stephenson, A. (2009). Horses in the sandpit: Photography, prolonged involvement and "Stepping Back" as strategies for listening to children's voices. Early Child Development and Care, 179(2), 131-141. https:/ / doi.org/10.1080/03004430 802667047

Stylianou, D. A., \& Silver, E. A. (2004). The role of visual representations in advanced mathematical problem solving: An examination of expert-novice similarities and differences. Mathematical thinking and learning, 6(4), 353-387. https:/ / doi.org/10.1207 /s15327833mt10604_1

Tyng, K. S., Zaman, H. B., \& Ahmad, A. (2011). Visual application in multi-touch tabletop for mathematics learning: A preliminary study. Paper presented at the International Visual Informatics Conference (pp. 319-328), Springer, Berlin: Heidelberg. https://doi.org/10.1007/978-3-64225191-7_31

van Garderen, D., Scheuermann, A., \& Jackson, C. (2013). Examining how students with diverse abilities use diagrams to solve mathematics word problems. Learning Disability Quarterly, 36(3), 145-160. https:/ / doi.org/10.1177/0731948712438558

Woleck, K. (2001). Listen to their pictures: An investigation of children's mathematical drawings. In A. A. Cuoco \& F. R. Curcio (Eds.), The roles of representation in school mathematics (pp. 215-227). Reston, VA: The National Council of Teachers of Mathematics.

Zahner, D., \& Corter, J. E. (2010). The process of probability problem solving: Use of external visual representations. Mathematical Thinking and Learning, 12(2), 177-204. https://doi.org/10.1080/ 10986061003654240

Zarzycki, P. (2004). From visualizing to proving. Teaching Mathematics and its Applications, 23(3), 108-118. https:/ / doi.org/10.1093/teamat/23.3.108

Zazkis, R., Dubinsky, E., \& Dautermann, J. (1996). Coordinating visual and analytic strategies: A study of students' understanding of the group D4. Journal for Research in Mathematics Education, 27(4), 435-457. https:/ / doi.org/10.2307/749876

\section{http://www.ejmste.com}

